\title{
El discurso contra la vagancia y su difusión a través de los bandos publicados en la Ciudad de México, 1810-1821
}

The Discourse against Vagrancy and its Diffusion through the Edicts Published in Mexico City, 1810-1821

\section{María del Carmen Raquel Moreno Ortíz}

Universidad Nacional Autónoma de México

Facultad de Estudios Superiores - Acatlán morenoraquel70@gmail.com

Cómo citar este artículo: María del Carmen Raquel Moreno Ortíz, "El discurso contra la vagancia y su difusión a través de los bandos publicados en la Ciudad de México, 1810-1821", en Legajos. Boletín del Archivo General de la Nación, núm. 15 (enero-abril 2018), pp. 11-34.

\section{Resumen}

Los vagabundos fueron considerados como individuos que rompían con las normas de la sociedad y causaban grandes perivicios. Combatir la vagancia fue, durante el siglo XVIII, parte del intento por reformar a la población capitalina, sin embargo, para el siglo xIX el proyecto tuvo que modificarse tras estallar la Guerra de Independencia. Este trabajo tiene por objetivo principal rastrear el discurso que circuló contra los vagabundos a través de los bandos de la Ciudad de México durante la década insurgente.

Palabras clave: vagos, criminalidad, Independencia, Ciudad de México, bandos

\section{Abstract}

The homeless were considered as individuals that broke with society's norms and caused great harm. Combating vagrant was during the $18^{\text {th }}$ Century part of the attempt to reform the capital's population; however, in the $19^{\text {th }}$ Century the project had to be modified after the War for Independence's eruption. This article seeks to track the discourse that circulated against the homeless through the edits of Mexico City during the insurgent decade.

Keywords: homeless, criminality, Independence, Mexico City, edict 


\section{Introducción}

Aun cuando algunos de los propósitos de las reformas borbónicas iban encaminados a frenar el desorden de las urbes, al iniciarse el siglo xix la Ciudad de México continuaba siendo percibida, como muchos ilustrados dieciochescos la habían descrito: una metrópoli desastrosa, desordenada y en ocasiones hasta repugnante, ${ }^{1}$ ya fuera por problemas de higiene o porque mendigos, ociosos y vagos deambulaban por la ciudad mostrando su pobreza, su aspecto andrajoso o sus escasas ropas.

Tanto para el siglo xvIII como para principios del xIx los vagabundos fueron considerados como individuos que rompían con las normas y causaban grandes perjuicios a la sociedad, combatir la vagancia era parte del intento por reformar a la población capitalina y para ello era necesario que se establecieran una serie de disposiciones que explicaran quiénes serían considerados como vagos y cuáles eran las medidas que se tomarían al respecto. Estos preceptos de carácter oficial fueron difundidos por medio de bandos, impresos oficiales, colocados en lugares estratégicos con la intención de que fueran visibles para todos los habitantes.

Este trabajo tiene por objetivo principal rastrear el discurso que circuló en contra de los vagabundos a través de los bandos de la Ciudad de México durante la Guerra de Independencia, pues por medio de los edictos que se decretaron en la época es posible acercarse a conocer qué se pensaba sobre la vagancia, por qué resultó importante perseguirlos en estos años de guerra y cómo estas ideas fueron difundidas mediante los impresos oficiales.

Para esta labor nos basamos en la plataforma digital Compendio de bandos de la Ciudad de México. Periodo Colonial en donde para los tiempos de 1810 a 1821 se hallaron cinco bandos.

\subsection{Entre el orden y el desorden. La Giudad de México a principios del siglo XIX}

A comienzos del siglo xix, la Ciudad de México continuaba siendo el más importante centro de reunión; entre sus calles se podía apreciar

${ }^{1}$ Dávalos, "La salud, el agua y los habitantes de la Ciudad de México", p. 281. 
una gran diversidad de grupos sociales que convivían en un mismo espacio; la ciudad era, entonces, un sitio donde se mezclaban personajes, costumbres y tradiciones.

En la urbe podían ya reconocerse algunos de los logros alcanzados por las reformas que había implementado la dinastía europea iniciada por Felipe de Anjou, como, por ejemplo, la reorganización del espacio urbano al modernizar las ciudades, de acuerdo con los ideales de la época, ordenando, embelleciendo y vigilando a las metrópolis hasta convertirlas en verdaderos "centros de irradiación del mensaje colonial". ${ }^{2}$

Con el plan de gobierno que los Borbón habían comenzado en el siglo xvin bajo la influencia de los principios de la Ilustración, se pretendía no solo llevar a cabo mejoras en sus territorios, sino también alcanzar "el perfeccionamiento de los hombres en los terrenos intelectual, moral y físico, es decir, un elemento básico para la felicidad individual y colectiva", ${ }^{3}$ por lo que fue necesario reglamentar no solo aspectos económicos y políticos, sino también circunstancias de la vida cotidiana.

La Ciudad de México debía convertirse, entonces, en "el modelo de las demás ciudades y lugares subalternos, así por la conducta de sus vecinos de todas las clases, propia de un país culto y morigerado, como por la construcción de sus edificios, limpieza y alumbrado de calles y plazas", ${ }^{4}$ sin embargo, limpiar la traza urbana infestada de mendigos, ociosos, malentretenidos y vagos resultaba algo bastante complejo.

Para alcanzar el esplendor del reino se consideraba indispensable no solo instruir y educar a cada uno de sus súbditos, sino que

\footnotetext{
${ }^{2}$ Ramón, "Urbe y orden: evidencias del reformismo borbónico en el tejido limeño", p. 299. ${ }^{3}$ Llombart, Fovellanos y el otoño de las luces, p. 55.

${ }^{4}$ Compendio de Bandos de la Ciudad de México, InAH. En línea: http://bandosmexico. inah.gob.mx/menu.html [consultado el 30 de mayo de 2017]. (Esta página contiene los bandos resguardados por el AGN ya digitalizados, en adelante se citará sólo la referencia de archivo). Bando publicado para la Ciudad de México por el virrey Francisco Xavier Venegas, Ciudad de México, 12 de octubre de 1810, ff. 332, AGN, Bandos, vol. 25, exp. 118.
} 
se requería también que fueran útiles a la Corona ya que al ilustrar, educar, instruir y tomar conciencia de que el trabajo llevaba a la felicidad económica y ésta era parte del bien común, "la ocupación de la gente será una máxima del gobierno, el cual ya no permitirá a la población vivir de la limosna, sino que tendrá que proporcionarle oportunidades de trabajo". ${ }^{5}$

La construcción de grandes obras públicas a lo largo del siglo XVIII e inicios del XIX $^{6}$ no solo embelleció la ciudad, ya que también fue un medio que sirvió para generar trabajo, aunque desempeñarse como panadero, barbero, carnicero, operario de fábrica, tocinero, vidriero, jabonero, zapatero, sastre o comerciante fueron oportunidades de trabajo que brindaron sustento y mantuvieron ocupados a un gran número de personas.

El ambicioso proyecto que se había planteado durante el siglo XVIII se prolongó hasta principios del xix, por lo cual, en la Ciudad de México, con el fin de utilizar "los elementos físicos urbanos como instrumentos pedagógicos", ${ }^{7}$ se continuó con la limpieza, el alumbrado y empedrado de calles, el desazolvado de acequias, intentando controlar los espacios públicos, reforzando la vigilancia y construyendo obras públicas.

Ya desde el siglo xvir se había tratado de dar respuesta a los conflictos de los sistemas económicos del siglo de las luces, sistemas preindustriales basados en la tierra y el trabajo, ${ }^{8}$ y una de las soluciones a las que se recurrió fue a la de "incorporar paulatinamente a la vida económica de la ciudad a quienes no tenían trabajo y a aquellos que llegaban desde fuera en busca de una ocupación; en ese sentido las obras publicas fueron un instrumento apropiado para este fin". 9

No obstante, un gran número de personas continuaban desocupadas, ya fuera porque tenían impedimentos para realizar algún

${ }^{5}$ Quiroz, Economía, obras públicas y trabajadores urbanos, p. 142.

${ }^{6}$ Véase Quiroz, Economía, obras públicas y trabajadores urbanos.

${ }^{7}$ Ramón, "Urbe y orden: evidencias del reformismo borbónico en el tejido limeño", p. 300.

${ }^{8}$ Llombart, Jovellanos y el otoño de las luces, p. 116.

${ }^{9}$ Quiroz, Economía, obras públicas y trabajadores urbanos, p. 124. 
trabajo, porque no hallaban dónde emplearse o no deseaban hacerlo. Por tanto, se estima que de lo que va entre los años de 1780 a 1820 , 130000 personas habitaban en la capital, de éstas solo las que tenían entre 17 y 60 años se encontraban en edad de trabajar, de las que se piensa que solo $55.6 \%$ tenían en qué emplearse, mientras que el otro $44.4 \%$ no contaban con una ocupación estable, es decir, se dedicaban al trabajo informal. ${ }^{10}$

Así pues, a causa del desprecio por la inutilidad y la ignorancia los vagabundos comenzaron a ser identificados -hombres y mujeres de cualquier calidad-, como una carga para la sociedad, individuos que andaban de un lugar a otro, que pudiendo trabajar no lo hacían, escandalosos, oportunistas, jugadores, viciosos, muchas veces relacionados con delitos como "el homicidio, la embriaguez, los robos, salteamientos y escalamientos de casas"; ${ }^{11}$ razones por las que constantemente fueron perseguidos.

En septiembre de 1810, estalló en Guanajuato el movimiento de Independencia y a pesar de que no sería hasta 1821 que el Ejército Imperial Mexicano entraría a la metrópoli, muy pronto comenzó a difundirse la idea de que algunos levantados se hallaban en la urbe colaborando con la insurgencia, fue por ello que, en aras de desconfianza, la justicia trató de reforzar aun más el cuidado del orden y la tranquilidad de la capital.

Mantener la seguridad en la capital era prioridad, así que la justicia sufrió algunas modificaciones durante los años del levantamiento. ${ }^{12}$ Para el año de 1810 se optó por el establecimiento de una policía militar con la fundación de la Junta de Alistamiento,

\footnotetext{
${ }^{10}$ Marichal, "Una difícil transición fiscal", pp. 95-103.

${ }^{11}$ Norman, Los vagabundos en la Nueva España XVI, p. VIII.

12 Véase en Nacif Mina, "Policía y seguridad pública en la Ciudad de México, 1770 1848”, p. 47. Antes la justicia y el cuidado del buen orden era parte de las tareas del intendente, que apoyado por el subdelegado y por los celadores públicos se encargaban únicamente de supervisar el orden de la ciudad, pues los juicios y las persecuciones no eran parte de su encargo, sino que a quien le correspondían era a la Real Sala del Crimen, dependiente de la Real Audiencia.
} 
conformada principalmente por españoles convocados por el virrey Francisco Xavier Venegas. Empero, la Junta no logró mantener la calma y el orden dentro de la capital. ${ }^{13}$

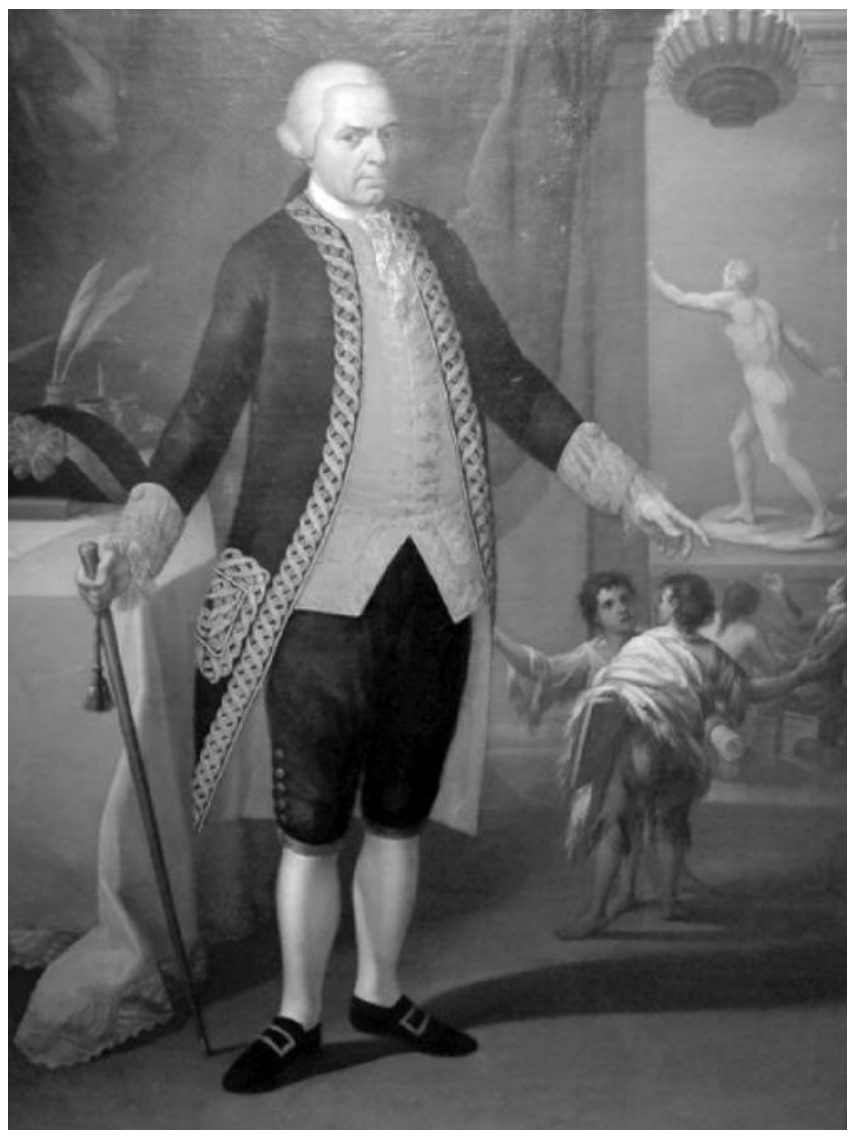

De igual modo, para el 17 de septiembre de 1810, Félix María Calleja, militar español, sería nombrado por el virrey, jefe de operaciones de la campaña para hacer frente a la amenaza insurgente. Calleja reclutó

${ }^{13}$ Ortiz Escamilla, "Insurgencia y seguridad pública en la Ciudad de México", p. 101. 
en su ejército a la gente útil de las ciudades, villas y pueblos, y la dotó de armamento. ${ }^{14}$

Un año después, se estableció la Junta de Policía y Tranquilidad Pública, que tenía como fin, además de perseguir la amenaza insurgente, también encargarse de quienes cometían delitos como el robo, el homicidio, la prostitución, la embriaguez y la vagancia; "para lograr tales objetivos, la junta se adjudicó atribuciones por encima de las autoridades como la Real Sala del Crimen, el ayuntamiento, los justicias y los subdelegados". ${ }^{15}$

La capital fue centro de atracción para muchos migrantes; en repetidas ocasiones "una serie de malas cosechas y epidemias forzó a los enfermos y hambrientos a escapar del campo en busca de auxilio y esta situación se agravó de nuevo después de 1810, cuando las guerras de Independencia enviaron a los refugiados a buscar abrigo en la capital". ${ }^{16}$ El constante flujo de migraciones propició que también se tuviera cuidado y se sospechara de los extranjeros, pues aunque éstos desempeñaban diversas ocupaciones, se temía que algunos pudieran ser gitanos, mendigos o vagos.

Pese a que se trató de designar a los desocupados al servicio de la Corona mediante las obras públicas, como "fuente de trabajo, no se resolvió el problema de la desocupación, que al parecer incrementó en 1811 a causa de las migraciones". ${ }^{17}$ Razón por la que posiblemente los trabajadores urbanos bien pudieron verse afectados a causa de la guerra, ya fuera por la carencia y el desabasto de algunos productos básicos, o por la suspensión o la menor inversión de recursos en obras públicas.

Aun cuando se sabe que durante los tiempos de guerra los adoberos, aguadores, alambreros, albañiles, cargadores, herreros y carpinteros continuaron ocupados en obras públicas, ocurrió, por ejemplo, que aunque "en 1815, el gobierno virreinal decidió finalmente construir

${ }^{14}$ Ortiz Escamilla, "Michoacán: el obispado en llamas", pp. 127-129.

${ }^{15}$ Ortiz Escamilla, "Insurgencia y seguridad pública en la Ciudad de México", p. 108.

${ }^{16}$ Arrom, Para contener al pueblo: el Hospicio de Pobres, p. 41.

${ }^{17}$ Quiroz, Economía, obras públicas y trabajadores urbanos, p. 164. 
una plaza de toros", ${ }^{18}$ ya que no resultaba fácil encontrar empleo en la ciudad, y entonces, motivados muchas veces por la falta de oportunidades, el desempleo, el hambre o la miseria, algunos desocupados o desafortunados no tardaron en sumarse a la lucha independentista. ${ }^{19}$

Uno de los grandes obstáculos que enfrentó el gobierno español para alcanzar el bien común, sin duda alguna, fue la desocupación de la población. A pesar de que se reglamentó en contra de los inútiles y de que constantemente se les persiguió con el fin de encausarlos a la utilidad, acabar con los males que causaban era algo sumamente difícil.

\subsection{Inútiles y peligrosos. El discurso oficial contra la vagancia en las disposiciones oficiales}

Debido a que la desocupación era uno de los constantes males que aquejaba a la ciudad, no resultó extraño que muchos fueran los bandos que se publicaran en contra de ésta; su publicación resultaba todo un espectáculo, pues el pregonero recorría "la Plaza Mayor acompañado por 'tambores y clarines' y deteniéndose sucesivamente frente al real palacio, la catedral y el ayuntamiento, leía en voz alta la cédula, el decreto o la real orden". ${ }^{20}$ Así, mientras por una parte el bando impreso y fijado en las paredes de la ciudad permitía a los lectores acercarse a la información, por otra, a quienes no leían, el grito del pregón y la oralidad les permitía continuar enterados de lo que sucedía a su alrededor.

Entre los miembros desocupados de la población pueden hallarse los pobres, que no tenían las capacidades y medios para mantenerse; los ociosos, aquellos que teniendo un lugar estable donde habitar no trabajaban ni se dedicaban al campo; los malentretenidos, personas sin oficio que se dedicaban al juego y al vicio; ${ }^{21}$ y los vagos, individuos que a pesar de encontrarse fuertes y sanos contaban con un extenso

\footnotetext{
${ }^{18}$ Viqueira Albán, ¿Relajados o reprimidos?, p. 43.

${ }^{19}$ Van Young, La otra rebelión. La lucha por la Independencia de México, p. 151.

${ }^{20}$ Lemperiere, Entre Dios y el rey, p. 250.

${ }^{21}$ Jurado Jurado, Vagos, pobres y mendigos, p. 43.
} 
tiempo de ocio, y que por desgana rechazaban el trabajo y vivían de su ingenio. ${ }^{22}$ Es de estos últimos de quienes nos ocuparemos las siguientes páginas, puesto que nos interesa conocer, debido a su constante mención en los bandos, cómo el vagabundo se convirtió en un peligro social y político durante la Guerra de Independencia.

\section{a) Holgazanes, mentirosos y falsos}

El primer bando encontrado que menciona a los vagos para el periodo comprendido de 1810 a 1821 data del día 7 de julio de 1810. En él se penaliza y prohíbe la reventa de billetes de lotería debido a que es una actividad de la cual solían ocuparse los vagos que en búsqueda de su beneficio los ofrecían a un precio más elevado del habitual; el castigo por el incumplimiento de esta disposición era la "multa de doscientos pesos, o en su defecto sufrirán dos meses de prisión", ${ }^{23}$ además de que "todo individuo que se encuentre vendiendo públicamente billetes será aplicado al servicio de armas por sospechoso de vago y malentretenido, y al hospicio de pobres, al que por su edad y circunstancias resultare inútil”. ${ }^{24}$

La instauración del Hospicio de Pobres en el año de 1774 dio lugar a que la distinción entre los verdaderos pobres, incapacitados de realizar trabajo, y los falsos pobres que en condiciones de trabajar no lo hacían, comenzara a evidenciarse. Así, mientras los "verdaderos pobres debían recibir 'amor y caridad' en el Hospicio [...] los vagos 'abominables' ser forzados a trabajar en el sector privado o sentenciados al servicio gubernamental", ${ }^{25}$ sin sueldo alguno, pero sí con raciones de comida.

Para el siglo xvin Gaspar Melchor de Jovellanos, escritor y político ilustrado español, manifestaba que "la solución del problema de la

${ }^{22}$ Arrom, Para contener al pueblo: el Hospicio de Pobres, p. 49.

${ }^{23}$ Bando publicado para la Ciudad de México por Real Audiencia Gobernadora, Ciudad de México, 7 de julio de 1810, ff. 108, AGN, Bandos, vol. 25, exp. 88.

${ }^{24}$ Bando publicado para la Ciudad de México por Real Audiencia Gobernadora, Ciudad de México, 7 de julio de 1810, ff. 108, agn, Bandos, vol. 25, exp. 88.

${ }_{25}$ Arrom, Para contener al pueblo: el Hospicio de Pobres, p. 47. 
pobreza, que es responsabilidad del Gobierno, no se encuentra principalmente en los hospicios, que sirven de 'alivio' más que de remedio", ${ }^{26}$ sino en que el gobierno explotara las fuentes de riqueza que ofrecían sus territorios, pues de esta manera podría alcanzarse el bien común y se "proporcionaría una mayor ocupación, especialmente a los indigentes sanos, predispuestos al trabajo y con un mínimo de formación". ${ }^{27}$

Lamentablemente, los vagos no parecían preocuparse mucho por contribuir a este fin ya que, de acuerdo con las ideas de ilustrados españoles como Bernardo Ward, Campomanes y Jovellanos, los vagos no hacían más que minar la riqueza de la monarquía. Además, con la intención de prevenir sublevaciones populares, tanto en España como en sus dominios, se pensó preciso "remediar la miseria de los 'verdaderos' indigentes y necesitados [sin embargo,] no implicaba por eso que se olvidara a los delincuentes ladrones y a otros criminales". ${ }^{28}$

La venta de billetes comenzó a regularse cuando, después de la publicación de la "Real Orden del 30 de abril de 1745, decisiva en todo el Imperio para la identificación de conductas y grupos sociales como los vagos, los ociosos y los malentretenidos", ${ }^{29}$ a los desocupados que subsistían de medios ilícitos y deshonestos nuevas características continuaron añadiéndoseles con el pasar de los años; así que para las fechas de la lucha llegaron a considerarse también como vagos no solo a los que no trabajaban y podían hacerlo, sino además a "quienes no trabajaban suficiente tiempo y aquellos que no trabajaban lo suficientemente duro". ${ }^{30}$ Tal y como sucedió constantemente con los trabajadores dedicados a actividades que se realizaban por ciclos, como los mineros, los artesanos o los agricultores, que en repetidas ocasiones sus hábitos se interpretaron como ocio, pereza o dejadez, ${ }^{31}$ razón por la que algunas veces fueron tomados por vagos.

\footnotetext{
${ }^{26}$ Llombart, Fovellanos y el otoño de las luces, p. 123.

${ }^{27}$ Llombart, Fovellanos y el otoño de las luces, p. 122.

${ }^{28}$ Langue, "Desterrar el vicio y serenar las conciencias", s. n.

${ }^{29}$ Jurado Jurado, Vagos, pobres y mendigos, p. 41.

${ }^{30}$ Arrom, Para contener al pueblo: el Hospicio de Pobres, p. 53.

${ }^{31}$ Jurado Jurado, Vagos, pobres y mendigos, p. 61.
} 
A pesar de que este bando fue publicado unos meses antes del inicio del movimiento insurgente, es evidente que las ideas de utilidad que comenzaron a surgir a lo largo de los siglos XVII y XVIII permearon aun el pensamiento de inicios del xix, y pese a que se extendió la idea de brindar auxilio a los pobres ya se buscaba distinguir a los verdaderos de los falsos.

\title{
b) Disciplina y corrección, las milicias son buena opción
}

El bando publicado el 10 de diciembre de 1810, aborda principalmente cuestiones de limpieza del agua y de los caminos; empero, en el punto número seis se hace énfasis en los vagos; en este impreso el virrey Francisco Xavier Venegas solicitaba:

\begin{abstract}
Que no conviene a la salud del pueblo y al buen orden el no consentir vagos ni malentretenidos y lo que sus achaques, edad u otras causas justas no pueden dedicarse a oficios tienen su recurso asegurado, sin molestia del público, en la Casa Real Hospicio de Pobres, donde sin limitación se recoge a todo aquel que califiquen los jueces por verdadero necesitado, dando aplicación a las armas o bajeles a los que no sean. ${ }^{32}$
\end{abstract}

Aunque una de las maneras más comunes para deshacerse de los individuos sin destino alguno, era el destierro (como ya se había planteado en las Leyes de Indias), ${ }^{33}$ tiempo después, el trabajo forzado, el

${ }^{32}$ Bando publicado para la Ciudad de México por el virrey Francisco Xavier Venegas, Ciudad de México, 12 de octubre de 1810, ff. 332, AGN, Bandos, vol. 25, exp. 118.

${ }^{33}$ En el tomo II, p. 284, Títulos cuarto y quinto, de los vagabundos y gitanos, en las Leyes primera, la segunda y la cuarta se menciona que a los españoles vagos que provocan daños y molestias a los indios no puedan habitar con ellos y se procure formar pueblos en los que se encuentren separados y en caso de que cualquier vago, sin importar su casta, no se emplee y continúe vagabundo será desterrado enviado a Chile o a Filipinas. Véase "Recopilación de Leyes de los Reynos de las Indias", Universidad de Sevilla, Fondos digitalizados, Fondo antiguo, En línea: http://fondosdigitales.us.es/fondos/libros/752/14/recopilación-de-leyesde-los-reynos-de-las-indias/ [consultado el 30 de septiembre de 2017]. 
servicio en las milicias y los proyectos de colonización comenzaron a convertirse en una buena alternativa para ellos, lo cual continuaría a lo largo del siglo XIx, pues de esta manera podían llevarse a cabo las obras necesarias para la mejora de la capital y se cuidaban los territorios que se encontraban bajo amenaza de invasión.

Una vez que se había tomado mediante levas a los sospechosos de vagancia, los hombres que cumplían con los 17 años de edad, de cinco pies de altura, en condiciones de realizar los ejercicios de la tropa, católicos y sin vicios eran asignados a las armas por un periodo de seis a ocho años. ${ }^{34}$ En cambio, los vagabundos que no cumplían estos requerimientos, como ya se mencionó, eran enviados a las obras públicas, minas o presidios. Por otro lado, las vagas, mujeres que en la mayoría de los casos quedan desprotegidas por sus familias o maridos, eran destinadas frecuentemente al servicio personal o a los corregimientos. La asignación de los vagabundos a las armas muy posiblemente comenzó cuando "las continuas guerras de España durante el siglo xvin y la necesidad de mejorar el control interno de sus colonias hicieron más necesario el fortalecimiento de los cuerpos militares", ${ }^{35}$ no obstante, esta medida pudo haberse radicalizado con la Guerra de Independencia en un intento por fortificar al ejército realista para la lucha contra los insurgentes.

El riesgo que representaban los vagabundos para esta época fue aumentando, pues se pensaba que a diferencia de la gente decente y leal a la Corona, los insurrectos no eran más que maleantes corrompidos. Por lo que no en vano, para "1812, Calleja aseguraba que [...] lo que más destacaba era haber conseguido que las 'personas honradas' se pasaran al bando realista. En cambio, entre los rebeldes la mayoría estaba conformada por prófugos de las cárceles, muchos de ellos ignorantes y miserables [...que] se dedicaban a hostilizar a las tropas, saquear haciendas, interceptar caminos e interrumpir los giros del comercio". ${ }^{36}$

${ }^{34}$ Jurado Jurado, Vagos, pobres y mendigos, p. 116.

${ }^{35}$ Jurado Jurado, Vagos, pobres y mendigos, p. 114.

${ }^{36}$ Ortiz Escamilla, "Michoacán: el obispado en llamas", p. 136. 
A pesar de la inquietante presencia de los vagos entre las calles de la ciudad "también los mendigos eran merodeadores, pero las autoridades

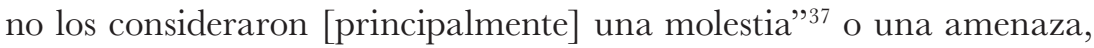
puesto que no tenían otra oportunidad de conseguir sustento más que el pedir limosna; y como el trabajo ya no era más un castigo de Dios, a diferencia de los mendigos, los vagos ya no eran vistos como "víctimas del desempleo, sino como gente perniciosa que sufría de un defecto moral que los llevaba a elegir su destino de manera voluntaria, de otra forma estarían empleados voluntariamente". ${ }^{38}$

Si bien, la vagancia no fue un problema exclusivo de un periodo en específico, pero posiblemente las ideas de los ilustrados influyeron para la construcción del discurso en contra de estos marginados, así que "la pobreza de grandes sectores de la población y la delincuencia no eran, pues, tan novedosos; tenían viejos antecedentes y parecían resurgir como un tema preocupante en coyunturas de reforma social y de reorganización política y fiscal". ${ }^{39}$

Se esperaba que al incorporar a los vagos a las milicias la disciplina de los batallones los preparara y los convirtiera en hombres útiles al Imperio que engrosaran las filas del ejército. Sin embargo, parece bastante paradójico que hombres a los que se les relacionaba con el ocio, la pereza y la estafa fueran alistados en la tropa, de modo que se podría pensar que hubo bastantes desertores.

\section{c) Por aquí y por allá, sospechosos en la capital}

El 13 de febrero de 1811 un nuevo bando fue expuesto en la capital del Virreinato, entre sus líneas podía leerse el temor por la entrada de insurrectos a la Ciudad de México y cómo es que se estableció un sistema de pasaportes por medio de los cuales trataría de regularse el movimiento de la población, tal como se muestra a continuación:

\footnotetext{
${ }^{37}$ Pérez Munguía, "Los vagos y las leyes de vagancia en Querétaro", p. 76.

${ }^{38}$ Arrom, Para contener al pueblo: el Hospicio de Pobres, p. 50.

${ }^{39}$ Jurado Jurado, Vagos, pobres y mendigos, p. 48.
} 
Conviniendo para el buen orden interior del reino en las presentes críticas circunstancias tener noticia exacta de las personas que transitan de unos lugares a otros, he juzgado necesario resolver que ningún individuo, de cualquiera estado, clase y condición que sea, salga de esta capital sin pasaporte mío, ni de la jurisdicción de su residencia a otra extraña sin llevarlo del subdelegado respectivo o sus tenientes [...] en la firme inteligencia de que el que caminare sin el expresado pasaporte, por el cual no se llevará derecho alguno, será arrestado por la justicia. ${ }^{40}$

La matanza del granero fue un duro golpe para el gobierno español y para la población de la Nueva España, puesto que, al "colocar en la mira de los ataques los símbolos del poder colonial también causaba temor entre la población [...]. Era, de alguna manera, presenciar el desmoronamiento de las instituciones de poder y de justicia que resguardaban su seguridad e integridad física". ${ }^{41}$ La incertidumbre aumentaba cada vez más conforme pasaban los años de guerra y estos desastres favorecieron al endurecimiento de las políticas de control social.

A pesar de que ya desde el siglo xvin se regulaba la movilidad de la población pidiendo que los súbditos informaran de su desplazamiento a las autoridades, ${ }^{42}$ ante las constantes migraciones que se presentaron durante la amenaza insurgente el miedo se encargó de construir no solo una dudosa imagen de todo aquel que deseara entrar a la gran urbe.

El temor por la llegada de los insurrectos a la Ciudad de México era indudable, las noticias de lo sucedido en la Alhóndiga de Granaditas

${ }^{40}$ Bando publicado para la Ciudad de México por el virrey Francisco Xavier Venegas, Ciudad de México, 13 de febrero de 1811, AGN/Archivo Histórico de Hacienda, vol. 1017, exp. 1.

${ }^{41}$ O'Phelan Godoy, "La construcción del miedo a la plebe en el siglo XVIII", p. 129.

${ }^{42}$ Dougnac Rodríguez, "Estatuto de las personas en el derecho indiano", p. 386. 
por la horda enfurecida que seguía a Hidalgo orillaron a las autoridades capitalinas a buscar maneras de prevenir todo tipo de ataques, por lo que los pasaportes parecían ser una alternativa de control social que brindaría seguridad a la capital; así pues, "ser viajero y no poseer un pasaporte significaba haber salido de su comunidad sin autorización y ameritaba ser juzgado como sospechoso insurgente; también podría ser acusado de vago o malviviente". ${ }^{43}$

Muchas de las razones por las que en realidad algunos individuos se unieron a las filas de la insurgencia se desconocen, pero se estima que "cambiar el mundo no fue siempre el interés de los sectores populares que participaron en ella" ${ }^{94}$ sino que en el movimiento los motivos económicos, políticos, sociales y hasta culturales, atrajeron a todo tipo de personas.

La desconfianza y la sospecha de que todo desconocido fuera parte de los insurgentes, influyó a que de cierta manera se fabricara también un discurso de sospecha y peligrosidad sobre los extranjeros, pues si no eran parte de los levantados, bien podían ser vagabundos, malvivientes o hasta insurrectos.

\section{d) Desarraigados y descarriados en la lucha}

Para el año de 1817, el virrey Juan Ruiz de Apodaca dio a conocer sus disposiciones a través del bando publicado el día 8 de enero; en él se pedía:

Que ninguna persona pasase de un lugar a otro del reino sin llevar el correspondiente pasaporte, insertando al efecto la instrucción que le pareció conveniente; y no permitiendo las circunstancias en que por desgracia se hallan estas provincias, a pesar de lo adelantada que está su pacificación, que se transite libremente por ellas, tanto

${ }^{43}$ Ortiz Escamilla, "Insurgencia y seguridad pública en la Ciudad de México", p. 104.

${ }^{44}$ Ríos Zúñiga, "Insurgencia y marginalidad en la intendencia de Zacatecas", p. 179. 
para distinguir a los fieles vasallos del rey nuestro señor de los que se hallan aún descarriados en la rebelión. ${ }^{45}$

\section{DON JUAN RUIZ DE APODACA Y ELIZA,}

Lanez de Lerowa + Lasetern, Gran Crus de las Reales Ordenes de San Fernando y San Hernentgildo, Comendador de Bellaga y Algarga en la de Calatrava, y de ta condecoracion de I Lis del Vendé, Ministro del Supremo Tribunal del Almirantargo, Teniente General de la Resl Armada, Virey, Gebernadoc y Capitan general de esta N. \&.. Presidente de st Real Audiencia, Saperintendente general Subdelegado de Real Hacierda, Minas, y Ramo de Tabaca, Juez Conservador de éste, President: de su Real Junts, y Subdelegado general de Correos en el mismo Reyeo dicc.

H

echo cargo de que si todos las partes del Superior Gobiano no cienen entre sf ena fintima conexion, y que si por atender $\dot{d}$ unas con empeío se descuidin otns, no se podra lograr el fin de li pubflea felicidad, tranquilidac de los babitantes de exte Vireynato, be puesto mi atencior en todas con quanta eficacia y exigencia pedian y me his sido posible

Asf es, cue siendo el sosiego y buen órden de las poblaciones uno de los mas importantes negecios del Gobierno, y que al proplo tiempo que se destruyen y castigan (cono corresponde) por indas partes i tas givillas de reteldes que cos las armas en la mano infestan estos territorios; es preciso que en las Cindades, Villuz y Lugares se persigan a los asesima, Ladrones $y$ malhechores de todas especies coadyuvando los vecinos hanridos con los Magiatrados hasta conseguir ef exterminio de tales politlas del Estado, $\gamma$ en justa proteccion á los fieles y rangauilos vasallos del Rey nusstm Señon.

A ese fin te cispuesto que con arreglo if la Iastruccion de Alcaldes de los Quirteles menomes, ronden tedos en esta Capital por horas de la noche: que lo haga igualmeate el sugeto encargado del despacho de Psaportes con los Guandas pagados y destinados al inteato: que igualmen. te lo verifiquen las Patrullas de infateria y caballeris que he considerads cuuveniontes; de mudo, que repartidos por los Quarteles $y$ tarrios no juede pange alguno que a sea visitado por ls noche, $\mathrm{y}$ estando vigilantes los Guardas del alumbrado, como los Vivaques y guardias de Preven. ciones + del recioto, se halien ea el caso de que no pueda intentarse delito que al menor aviso no lo paedau precaver, ni if lega el caso de cometerse no se aprehenda al delinqüente y auxillie al necesitado, $y$ como rodas estas nedidas estio vigilacas jara su cumplimiento por os Sef́ores Ge$\mathrm{f}: \mathrm{s}$ de dia, y Señores Jeeces de los Quarteles mayores, twe promew, que as! como la experiencía me ha dado á conocer en los dias que lleva de efectivo eate plan, bo úril de el por la dininacion de los desordenes, segun les partes cue recibo' contipuando con el zzlo y teznn que es nerecario en todos, conseguiré el to que me he propaesto en bien del servicio de $\mathrm{S}$ M. Y del púbica. 3 Taies-medidas en esta Capital poćrias prodacir al mismo tiempo que el bien de sus vecinos, vo wal para los que lo fueten de las demas Ciudades, Villas y Lugares cel Vireynito, si en todss ellas no se adoptasen iguales medidas que las establecidas aquil: pues baxo la impanidad que en aquellas disfrutarian, se trasladarian i ellas infestandose de todos los malhechores que fugasen do esta por tenor de su persecucion, y por la imposijilidad de cometer en ella sus erímenes.

En vista de todo mando, que al exemplo de esta Capial y en donde hubiere igules propor. ciones se establezca igual órden de Rondas y vigilancia que queda dicho: que en los lugares donce no las baya, las Gobernadores, Corregidores, Alcaldes ó Justicas las establezcaz del modo posible, empliando á los fieles Realistas y vecinos tovorados en ellas, haciéndolas frequentes por sí mismos, y tomando todos los conocinientos posibles de los malhechores para aprehenderlog juzgarlos y castigarlos conforme tlas leyes, y á bs vagos aplicarlos á las armas; siguiendo mn el mayor esmero este tan importante servicio, no perdonarin fatiga ni dilizencia hasta conseguir el fa ce que caca recino con su fanilia goce pacíficamente de los beneficios de su trabajo, aplicacion é indestria, baxo la proteccion de los Gefes y Magistrados que S. M. les ha puesto para que les administren justicia y liberten de los malvados: sizudo aquellos responsables de qualquiera saceso deigriciado si inmediatamente, publicada esta disposicion por Bando o llegada í su noticia, no establecen las Rondas y Patrullas ordenadas $\mathrm{A}$ cuyo in así se hari en los términos acostumbra. dos, circulindose á quieses corresponda. Dado en Mérico 28 de Enero de 1817.

Jwan Ruis de Apodaca

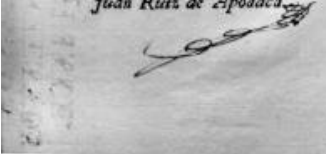

Por mandado de S. B.

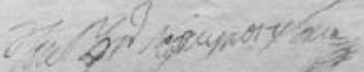

${ }^{45}$ Bando publicado para la Ciudad de México por el virrey Juan Ruiz de Apodaca, Ciudad de México, 11 de noviembre de 1818, AgN, Jesuitas, caja II-34, folder 55. 
Para este año la preocupación por el movimiento ha incrementado, si bien, se siguen manteniendo los pasaportes, las rondas fueron otra medida de seguridad que se llevó a cabo con el fin de tener un mayor control sobre los espacios de la capital durante la guerra; para ello, Apodaca pedía que se recurriera a los vecinos honrosos, de buenos valores y, sobre todo fieles realistas; probablemente por el temor a que la seguridad se viera corrompida.

Durante plena lucha de Independencia el discurso se había modificado, se construyó al personaje del vago como un defectuoso moral, un vividor, un individuo improductivo, escandaloso, posiblemente criminal o insurgente, enemigo de la felicidad pública, del bien común y una amenaza para la preservación del virreinato.

La atribución criminal al vagabundo se encuentra, entonces, vinculada a la región, a sus necesidades, causas e intereses, por lo que podría ser explicada de la siguiente manera: "un cierto grupo de personas advierte que uno de sus propios valores -vida, propiedad, belleza del paisaje, doctrina teológica- es puesto en peligro por el comportamiento de otros. Si el grupo es políticamente influyente, el valor importante y el peligro serio, los mismos del grupo se asegurarán la promulgación de una ley". ${ }^{46}$

Atentar contra los ideales y las normas explícitas e implícitas de la sociedad fueron razones para que estos hombres sin destino fueran usualmente relacionados con diversos tipos de delitos, ya que se pensaba que "al no tener un empleo fijo, se veían obligados a robar para obtener lo que necesitaban para comer, pagar las deudas de juego que habían contraído o desempeñar la ropa u otros objetos que habían dejado en tiendas, vinaterías y pulquerías", ${ }^{47}$ además "la concepción utilitarista del trabajo [...] en la que ya nadie tuviese que ser mantenido por mera piedad [...] se relacionó también con el modo de entender el vagabundaje como delito". ${ }^{48}$

\footnotetext{
${ }^{46}$ Casagrande, Los vagabundos y la justicia de Buenos Aires, p. 61.

${ }^{47}$ Lozano Armendares, La criminalidad en la Ciudad de México, 1810-1821, p. 35.

${ }^{48}$ Quiroz, Economía, obras públicas y trabajadores urbanos, p. 40.
} 
De igual modo, a comienzos del siglo xix en Perú los vagabundos fueron percibidos también como "alteradores del orden público; individuos de escasos recursos con trabajos eventuales o desocupados y, por lo tanto, proclives al ocio, al robo, a la violencia, a la insubordinación". ${ }^{49}$ Es por esto que, para 1826, tras concluir la emancipación peruana, y comenzar la construcción de un nuevo proyecto de gobierno, continuó presente el miedo a que los vagos se sublevaran; así pues, al igual que en el virreinato de la Nueva España, "el temor a que rebasaran el control social del sistema no se borrará fácilmente de la mente de las autoridades republicanas". ${ }^{50}$

El temor que la elite y las autoridades coloniales tenían por la sublevación de los grupos menos favorecidos, puede verse reflejado en "el desarrollo durante el Antiguo Régimen de esquemas clasificatorios cada vez más complejos para identificar y diferenciar a los pobres [que] constituye un signo de la evolución de las mentalidades colectivas y las estructuras sociales". ${ }^{51}$ Con la Independencia, la persecución de los vagos se convirtió principalmente en una causa práctica con la que se intentó controlar no sólo a los vagabundos, sino a todos aquellos viajeros que resultaran sospechosos, a los criminales y, sobre todo, a los insurgentes.

\section{Consideraciones finales}

Los bandos que se han expuesto anteriormente denotan ya una preocupación por la sospecha de que los vagos se incorporaran a la guerra, excepto el del 7 de julio de 1810. En ellos puede apreciarse cómo las autoridades continuaron llevando a cabo muchas de las políticas que se habían implementado desde el siglo xvi en contra de la vagancia; sin embargo, éstas no se ajustaron solo a las ideas de utilidad y bien común que se gestaron durante los siglos XviI y xviII, sino que, contingentemente, conforme avanzaba la Guerra de Independencia,

${ }^{49}$ O’Phelan Godoy, "La construcción del miedo a la plebe en el siglo XVIII", p. 124.

${ }^{50}$ O'Phelan Godoy, "La construcción del miedo a la plebe en el siglo XvIII", p. 136.

${ }^{51}$ Bolufer Peruga, "Entre historia social e historia cultural", p. 110. 
se modificaron por unas que parecieran más adecuadas y prácticas para el momento.

En las disposiciones aquí analizadas se difunde la idea de un vagabundo oportunista, desagradable a la vista, que no trabaja porque no desea hacerlo, del cual había que aprovechar su fuerza de trabajo. Además, conforme va adquiriendo fuerza el levantamiento, el vago adquiere también cualidades como las de criminal e insurrecto que le llevan a convertirse en un individuo peligroso social y políticamente.

En el discurso oficial el régimen tuvo también que mostrar cómo, a pesar de que el vago podía trabajar en las múltiples oportunidades de empleo que el gobierno español ofrecía, es decir, en las numerosas obras públicas que se llevaron a cabo, en las milicias, en las fábricas, las minas, etcétera, y cómo, además, desde el siglo XviII también se trató de restar poder a los gremios, puesto que se pensaba que "estorbaban la creación de nuevos oficios e impedían la unión entre la industria y la labranza", ${ }^{52}$ la idea de un vago que, por decisión propia no tenía intenciones de trabajar continuó presente.

Si bien, es verdad que había oportunidades para laborar, pareciera ser que las fuentes de ocupación que el gobierno ofreció no fueron suficientes y, aunque probablemente existían otras causas que conducían a la vagancia, presentar al vago como un sujeto inútil al cual era necesario destinar al trabajo forzado en vez de enviarlo a la cárcel ya que no contribuía con el bien común, resultó bastante útil tanto para el siglo XVIII como para principios del XIx.

La esperanza de convertir al vagabundo en una persona útil respondió en un principio a las ideas del utilitarismo y del bien común; no obstante, para los tiempos del movimiento armado pareciera ser aún más frecuente destinarlos a las armas. Además, la constante mención de los vagos en las disposiciones oficiales pudiera ser porque al ser un concepto bastante elástico permitió englobar y atrapar a todo sospechoso, tanto interno como foráneo, ladrón, homicida, ebrio e insurgente.

${ }^{52}$ Illades, "Organizaciones laborales y discurso asociativo en el siglo XIX", p. 252. 
Poco es lo que se menciona sobre las mujeres o los niños vagos en la legislación y en los bandos. Muchos de los niños que por alguna razón quedaban huérfanos eran enviados a la casa de niños expósitos; sin embargo, "los hijos de los mendigos tanto niñas como niños, habrían de ser colocados como aprendices de algún maestro acreditado o en un asilo para que aprendieran un oficio". ${ }^{33}$ Por otra parte, las mujeres abandonadas o viudas que no conseguían alguna ocupación y recurrían a la vagancia eran consignadas usualmente al servicio personal o a los corregimientos, pero aun parece ser poco lo que se sabe de ellos.

Para entender lo amenazante que puede resultar un individuo o un grupo, éste debe ser abordado como un fenómeno que se transforma dentro de una sociedad y que muta de acuerdo con los valores e intereses de la misma. Por lo tanto, podríamos pensar que la criminalización del vagabundo posiblemente puede establecerse a través del riesgo que representa para un lugar y época. Así pues, para finales del xvi y principios del xvin la legislación optó por el trabajo forzado para los vagos con el fin de volverlos útiles, mientras que para inicios del XIx designarlos a las fuerzas armadas fue usual, es decir lo que "determinó la condición criminal de un conjunto de actos y/o actores consistió en una serie de representaciones negativas sobre esa otredad que vivía y se desenvolvía en los márgenes de la sociedad". ${ }^{54}$

La idea de vago que se difundió en las disposiciones oficiales pretendía no solo regular el comportamiento y poner fin a las malas costumbres de estos marginados, sino también ejemplificar lo que un buen súbdito no debía ser o hacer, pues el interés de poner fin a la vagancia muchas veces respondió a los ideales de la época, a la cultura, al lugar, a los intereses económicos, además del temor de la elite y las autoridades por la sublevación de los grupos menos favorecidos, lo que se vio reflejado en el discurso construido alrededor del vagabundo, individuo que no encajaba con los ideales del gobierno español desde el siglo xvi, y menos aún, en el xix cuando se convirtió en una amenaza para la preservación del régimen.

${ }^{53}$ Arrom, Para contener al pueblo: el Hospicio de Pobres, p. 51.

${ }^{54}$ Casagrande, Los vagabundos y la justicia de Buenos Aires, p. 62. 


\section{Fuentes}

\section{Bibliografía}

\section{Libros}

Arrom, Silvia Marina, Para contener al pueblo: el Hospicio de Pobres de la Ciudad de México (1774-1871), México, ciesas, 2010.

Jurado Jurado, Juan Carlos, Vagos, pobres y mendigos. Contribución a la historia social colombiana, Medellín, Laca Carreta, 2004.

Lemperiere, Annick, Entre Dios y el rey: la república. La Ciudad de México de los siglos, México, FCE, 2013.

Llombart, Vicent, Fovellanos y el otoño de las luces. Educación, economía, politica y felicidad, Guijón, Ediciones Trea, 2012.

Norman, Martin F., Los vagabundos en la Nueva España xи, México, Editorial Jus, 1957.

Quiroz, Enriqueta, Economía, obras públicas y trabajadores urbanos. Ciudad de México: 1687-1807, México, Instituto de Investigaciones Dr. José María Luis Mora, 2016.

Viqueira Albán, Juan Pedro, ¿Relajados o reprimidos? Diversiones públicas y vida social en la Ciudad de México durante el siglo de las luces, México, FCE, 1987.

\section{Capítulos de libros}

Dávalos, Marcela, "La salud, el agua y los habitantes de la Ciudad de México. Fines del siglo XVIII y principios del xIx", en Hernández Franyuti, Regina (coord.), La Ciudad de México en la primera mitad del siglo XIX, t. II, México, Instituto de Investigaciones Dr. José María Luis Mora, 1994, pp. 95-124, 279-302. 
Dougnac Rodríguez, Antonio, "Estatuto de las personas en el derecho indiano", en Manual de historia del derecho indiano, México, unam, 1998, pp. 313-398.

Illades, Carlos, "Organizaciones laborales y discurso asociativo en el siglo xIx", en Carlos Illades y Ariel Rodríguez Kuri (comps.), Ciudad de México. Instituciones, actores y conflicto político. 1774-1931, México, El Colegio de Michoacán, 1996, pp. 245-274.

Marichal, Carlos, "Una difícil transición fiscal: del régimen colonial al México independiente, 1750-1850", en Carlos Marichal y Daniela Merino (comps.), De Colonia a Nación. Impuestos y política en México, 1750-1860, México, El Colegio de México, 2001.

Nacif Mina, Jorge, "Policía y seguridad pública en la Ciudad de México, 1770-1848”, en Hernández Franyuti, Regina (coord.), La Ciudad de México en la primera mitad del siglo XIX, t. II, Instituto de Investigaciones Dr. José María Luis Mora, 1994, pp. 9-50.

O'Phelan Godoy, Scarlett, "La construcción del miedo a la plebe en el siglo XVIII a través de las rebeliones sociales", en Claudia Rosas Lauro (ed.), El miedo en Perú. Siglos xvi al xx, Lima, Pontificia Universidad Católica del Perú, Fondo Editorial, 2005, pp. 123-138.

Pérez Munguía, Patricia, "Los vagos y las leyes de vagancia en Querétaro: continuidades y rupturas entre la Colonia y el siglo xIx", en Romana Falcón, Culturas de pobreza y resistencia. Estudios de marginados, proscritos y descontentos en México, 1804-1910, México, El Colegio de México, 2005, pp. 73-97.

Ortiz Escamilla, Juan, "Insurgencia y seguridad pública en la Ciudad de México, 1810-1815”, en Hernández Franyuti, Regina (coord.), La Ciudad de México en la primera mitad del siglo XIX, t. II, México, Instituto de Investigaciones Dr. José María Luis Mora, 1994, pp. 95-124. 
, "Michoacán: el obispado en llamas", en José Antonio Serrano Ortega, La guerra de Independencia en el obispado de Michoacán, México, El Colegio de México, 2010, pp. 125-151.

Ramón, Gabriel, "Urbe y orden: evidencias del reformismo borbónico en el tejido limeño", en Scarlett O'Phelan Godoy (ed.), El Perú en el siglo xviII. La era Borbónica, Lima, Pontificia Universidad Católica del Perú, Fondo Editorial, 2015, pp. 299-328.

Ríos, Zúñiga Rosalina, "Insurgencia y marginalidad en la intendencia de Zacatecas, 1810-1821", en Ana Carolina Ibarra (coord.), La Independencia en el septentrión de la Nueva España. Provincias internas e intendencias norteñas, México, unam, 2010, pp. 177-213.

\section{Tesis}

Casagrande, Agustín Elías, "Los vagabundos y la justicia de Buenos Aires durante el periodo tardo colonial (1785-1810): Construcciones jurídicas y criminalidad", tesis para la obtención del grado de Magíster en Ciencias Sociales, Buenos Aires, Facultad de Humanidades y Ciencias de la Educación, Universidad Nacional de la Plata.

\section{Artículos}

Bolufer Peruga, Mónica, "Entre historia social e historia cultural. La historiografía sobre pobreza y caridad en la época Moderna", en Historia Social, núm. 43, 2002, pp. 105-128. En línea: https:// dialnet.unrioja.es/servlet/autor?codigo $=214745$ [consultado el 26 de septiembre de 2017].

Langue, Frederique, "Desterrar el vicio y serenar las conciencias. Mendicidad y pobreza en la Caracas del siglo xvin", en Nuevo mundo, mundos nuevos. En línea: https://nuevomundo.revues.org/629 [consultado el 26 de septiembre de 2017]. 


\section{Páginas electrónicas}

Compendio de Bandos de la Ciudad de México, inah. http://bandosmexico.inah.gob.mx/menu.html [consultado el 30 de mayo de 2017].

Bando publicado para la Ciudad de México por la Real Audiencia Gobernadora, Ciudad de México, 7 de julio de 1810, ff. 108, AGN, Bandos, vol. 25, exp. 88.

Bando publicado para la Ciudad de México por el virrey Francisco Xavier Venegas, Ciudad de México, 12 de octubre de 1810, ff. 332, AGN, Bandos, vol. 25, exp. 118.

Bando publicado para la Ciudad de México por el virrey Francisco Xavier Venegas, Ciudad de México, 13 de febrero de 1811, AGn, Archivo Histórico de Hacienda, vol. 1017, exp. 1.

Bando publicado para la Ciudad de México por el virrey Juan Ruiz de Apodaca, Ciudad de México, 8 de enero de 1817, AGn, ff. 10, Bandos, vol. 29, exp. 3.

Bando publicado para la Ciudad de México por el virrey Juan Ruiz de Apodaca, Ciudad de México, 11 de noviembre de 1818, Agn, Jesuitas, caja II-34, folder 55 . 